\title{
Assessing farm-based measures for mitigating human-elephant conflict in Transmara District, Kenya
}

\author{
Noah W. Sitati and Matthew J. Walpole
}

\begin{abstract}
Crop raiding by elephants is widespread across Africa and Asia. Although many traditional and novel methods are used to defend farms there have been few rigorous tests of their efficacy. We provide a comparative quantitative assessment of a range of farmbased mitigation methods implemented during a 4-year project in Transmara District, Kenya. Five experimental trials were established to measure changes in crop raiding after the application of mitigation methods on treatment farms compared with control farms. A combination of early warning to detect elephants before
\end{abstract}

they entered farms, coupled with a front line communal guarding strategy, proved most successful. Non-electrified barriers were expensive and generally ineffective. However, chilli Capsicum spp. grease applied to rope barriers encircling farms completely deterred elephants. Although encouraging, these results require more widespread testing and demonstration to ensure their effectiveness at broader scales.

Keywords African elephant, crop raiding, humanwildlife conflict, Masai Mara, mitigation methods.

\section{Introduction}

Human-wildlife conflict threatens the survival of many large mammals both inside and outside protected areas (Woodroffe \& Ginsberg, 1998) and finding solutions to conflict is a conservation priority (Hill et al., 2000; Woodroffe et al., 2005). Human-elephant conflict, and particularly crop raiding, is a perennial problem in both Africa and Asia. In Africa it has become increasingly significant as human populations expand and encroach on elephant habitat (Hoare \& du Toit, 1999; Hoare, 2000a) and as elephant populations expand from protected refuges into unprotected historical range (Walpole et al., 2004). Although not a new problem, its apparent increase threatens conservation efforts for elephants.

Government compensation schemes for humanelephant conflict have proved difficult to administer and do not actually reduce crop raiding, and many compensation schemes have been abandoned as unworkable (Bell 1984; Hoare 2000b, 2001). Equally, expensive and high-tech interventions favoured by donors and wildlife management agencies, such as electric fencing and translocation, demand resources and expertise that are beyond the reach of most rural communities (Thouless \&

\footnotetext{
Noah W. Sitati and Matthew J. Walpole* (Corresponding author) Durrell Institute of Conservation and Ecology, University of Kent, Canterbury, Kent, CT2 7NS, UK. E-mail matt.walpole@fauna-flora.org

${ }^{*}$ Current address: Fauna \& Flora International, Great Eastern House,

Tenison Road, Cambridge, CB1 2TT, UK.

Received 15 December 2004. Revision requested 20 April 2005.

Accepted 19 September 2005
}

Sakwa, 1995; Njumbi et al., 1996). Lethal control by wildlife agencies removes individual problem animals but does not necessarily deter others, and these agencies cannot respond to every incident.

Given these limitations, most rural communities must defend their farms themselves. Numerous inexpensive, low-tech, non-fatal mitigation methods are used across both Africa (Bell, 1984; Hoare, 2001) and Asia (Sukumar, 1989; Nyhus et al., 2000). These include passive barrier methods (such as ditches, fences, walls and hedges) and active deterrents (including shouting, banging tins and drums, throwing stones, lighting fires and burning chillies Capsicum spp.). Placing the responsibility for human-elephant conflict mitigation with communities, and assisting them in the application of simple, costeffective, farm-based measures may be the most sustainable option (Osborn \& Parker, 2003). Communities themselves usually have an opinion about which methods are most effective (Hill, 2000; Nyhus et al., 2000). However, there have been few documented, objective tests.

Studies in Namibia showed that early warning systems to alert farmers to approaching elephants were relatively successful in small-scale trials (O'ConnellRodwell et al., 2000). Equally, in Zimbabwe, chilli spray reduced the amount of time elephants spent within crop fields (Osborn \& Rasmussen, 1995; Osborn, 2002; Osborn $\&$ Parker, 2002). However, evidence also suggests that mitigation efforts may simply displace elephants to other farms in the short-term, and in the longer term elephants may habituate to these false threats (Bell, 1984; Tchamba, 1996; O'Connell-Rodwell et al., 2000). 
The persistence of human-elephant conflict attests to the lack of an all-encompassing technical solution. However, it may also stem from poor implementation because of a lack of faith amongst farmers, alongside the costs required to maintain adequate defences (Osborn \& Parker, 2003). To identify which mitigation methods work best and to demonstrate this to farmers, comprehensive trials are required across a range of conflict scenarios. Such evidence-based conservation is fundamental to the management of practical conservation problems (Sutherland et al., 2004). This paper describes a medium-term study designed to test a range of simple, cost effective, traditional and novel mitigation methods that are accessible to rural communities without major external support.

\section{Study area}

Transmara District $\left(2,900 \mathrm{~km}^{2}\right)$ lies in south-western Kenya bordering Tanzania. It encompasses the western portion of the Masai Mara National Reserve. Approximately 2,200 $\mathrm{km}^{2}$ is inhabited and unprotected (Fig. 1). Total annual rainfall is 1,200-1,500 $\mathrm{mm}$ and falls in a bimodal pattern (March-June and NovemberDecember) with a north-south gradient of high to low rainfall across the district. The natural vegetation is a mosaic of Afro-montane, semi deciduous and dry deciduous forests and Acacia savanna. However, many areas of the district have high agricultural potential and cultivation is widespread. For a full description of the area see Sitati et al. (2003). The remaining forest provides refuge for a resident, unprotected population of 200-300 elephants that once ranged across most parts of the District, but that now extend over $<1,000 \mathrm{~km}^{2}$. A larger population of $c$. 1,600 elephants resides mainly within the Reserve (Blanc et al., 2003).

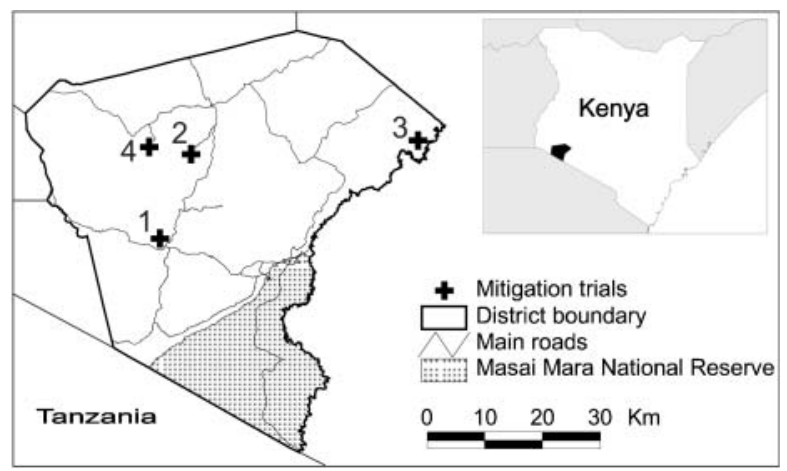

Fig. 1 Map of Transmara District in south-west Kenya, showing location of mitigation trials (crosses): (1) Lolgorien, watchtowers and chilli rope; (2) Olalui, thunder flashes; (3) Emarti, barriers;

(4) Nkararu, chilli rope. The inset indicates the location of the main figure in Kenya.
Increasing human and elephant populations and rapid agricultural expansion has increased conflict within the district. Both people and elephants suffer injury and death, and attitudes towards elephants in the district are generally negative (Sitati, 2003; Walpole et al., 2003). Rural communities receive little support from the national wildlife authority, Kenya Wildlife Service, because of limited resources and personnel. Consequently, local communities use traditional mitigation measures to keep elephants from their farms. These include simple non-electrified barriers (dry brush, pole fences and barbed wire), guarding, lighting fires and banging tins and drums. A comparison of raided and non-raided farms in Transmara suggested that a combination of early detection of elephants, increased guarding, and deterrents such as fire and noise used by some local farmers, were most associated with the successful defence of farms (Sitati et al., 2005). However, both the financial and non-financial costs of establishing mitigation methods mean that they are often poorly or patchily implemented. As a result, local people have little faith in these methods (Sitati, 2003).

\section{Methods}

\section{Community-based conflict monitoring}

During April 1999-August 2000 and September 2001October 2003 all crop-raiding incidents in Transmara District were recorded using a standardized reporting form (Hoare, 1999) by a team of 11 local community scouts stationed at different locations within the elephant range. Each incident was visited for verification and to interview the farmer concerned. The date, time, location (using a global positioning system), amount of damage and a range of other factors regarding the incident were recorded (Sitati et al., 2003).

\section{Human-elephant conflict mitigation trials}

In an attempt to emulate an experimental research design we applied treatments (new mitigation methods) part way through the monitoring period to a sub-sample of farms, leaving others nearby as untreated controls. Beginning in September 2001 five mitigation trial sites were established within four different conflict zones, each testing a different mitigation method. They were monitored continuously until October 2003 and trained observers recorded details of attempts by elephants to challenge trial farms. The five trials included:

1) Front line early warning and communal guarding The 14 farmers of the Ilmejoli Farmers Association near Lolgorien (Fig. 1) were assisted with improved detection and communal guarding. Two treetop 


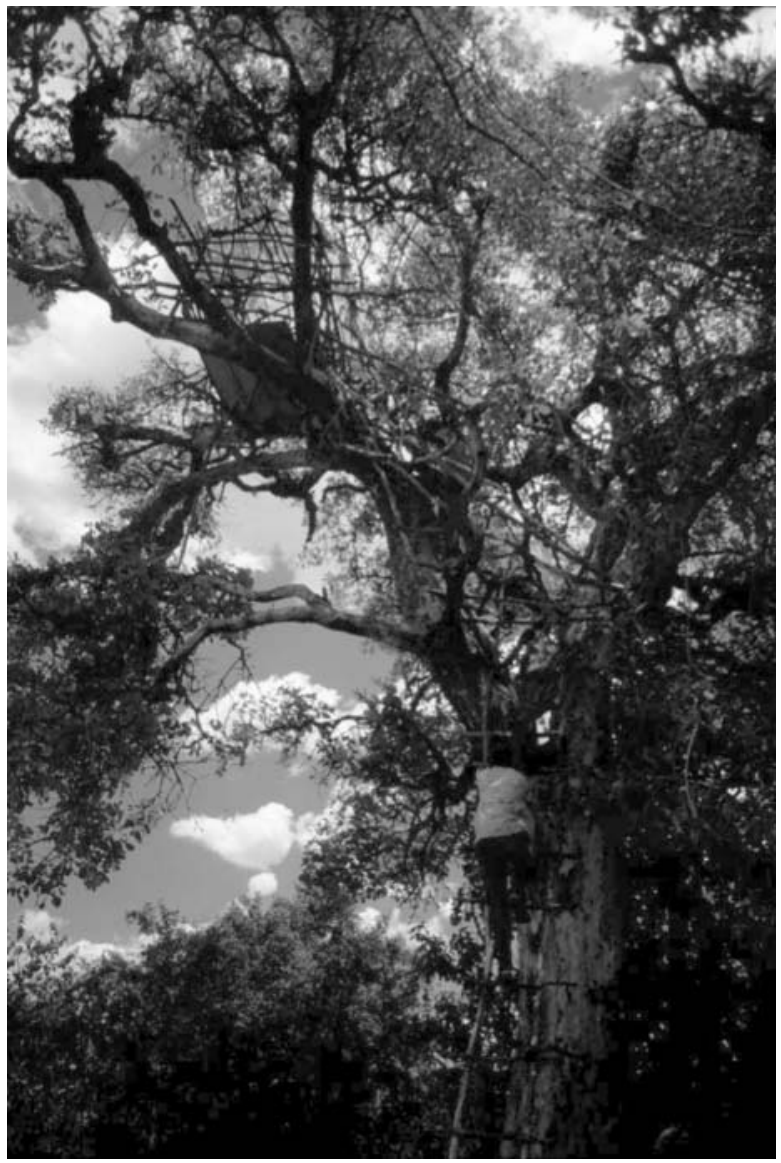

Plate 1 Watchtower constructed adjacent to front line farms in Lolgorien, Transmara District, to facilitate communal guarding and early warning of elephant approach (Matt Walpole).

watchtowers (11 $\mathrm{m}$ above the ground) were erected and manned by nine farmers on a rotational basis, using powerful torches to detect elephants emerging from the forest (Plate 1). Fires were lit around the farms for clear visibility. People living in an elephant corridor beyond the front line farms used torches and whistles as an additional early warning system. Once elephants were detected farmers used torches, whistles and drums in the traditional way to prevent elephants entering fields. A comparative group of farms 2-3 km away, with similar levels of crop raiding, provided a control.

2) Thunder flashes A retired military officer living in a core elephant range at Olalui (Fig. 1) was provided with thunder flashes (hand-held fire-crackers producing a loud noise and bright light when detonated by lighting a fuse) to scare away elephants at night. These were supplied on license by the Kenya Wildlife Service. The trial was reinforced with a treetop watchtower and use of powerful torches to provide early warning as in trial (1) above.
3) Barriers on elephant crop-raiding routes Non-electrified barriers around farms are generally ineffective against elephants. However, in one area adjacent to the Mara River the strategic deployment of stronger barriers at elephant crossings along the riverbank was proposed as a way of preventing elephants getting close to farms. Five post and wire fences were erected at Emarti, in the elephant crossings along the western banks of the Mara River close to raided farms (Fig. 1). Fence guards recorded attempts by elephants to challenge these barriers.

4) Chilli grease deterrent The use of chilli essence to deter elephants was developed in Zimbabwe (Osborn \& Rasmussen, 1995; Osborn, 2002) and is increasingly promoted throughout Africa as a mitigation tool (Duncan, 2003). Chilli essence had not previously been used in Transmara. Two different trials of chilli essence applied to simple rope barriers were designed. Firstly, a $1.4 \mathrm{~km}$ long perimeter fence of nylon rope (10 $\mathrm{mm}$ diameter, available locally) was erected along the front line farms in Nkararu, a high conflict zone, at a height of $1.5 \mathrm{~m}$ above the ground (Fig. 1). A mixed grease of used engine oil, chilli and tobacco was regularly applied to the rope. Twelve cowbells were fixed to the rope at $100 \mathrm{~m}$ intervals as an early warning system. Farmers were equipped with powerful torches to respond to elephant approaches. Attempts by elephants to crop raid were observed and recorded by a trained guard. Secondly, a 4-acre, isolated and habitually raided farm located in an elephant corridor near Lolgorien (Fig. 1, Plate 2) was encircled with a chilli rope fence. A treetop watchtower was erected in the middle of the farm to assist guards as in trial (1).

\section{Analysis}

Both time series comparisons of crop raiding on trial farms and spatial comparisons of change on trial and

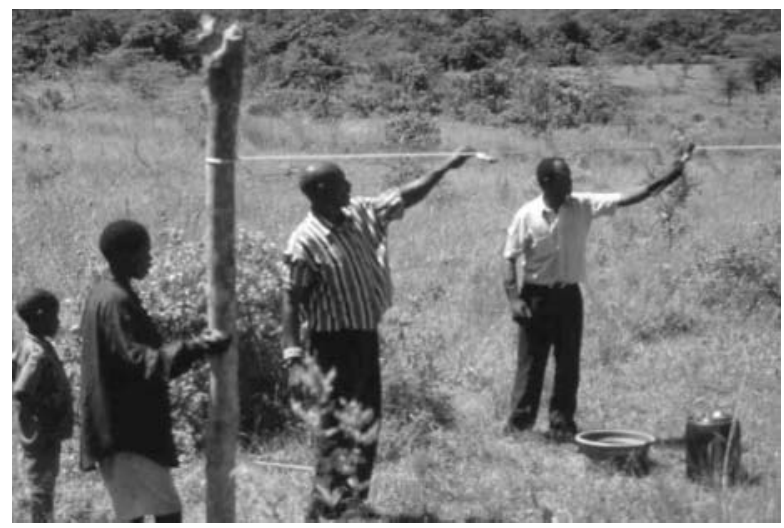

Plate 2 Chilli grease being applied to a rope fence around a farm in Lolgorien, Transmara District (Noah Sitati). 


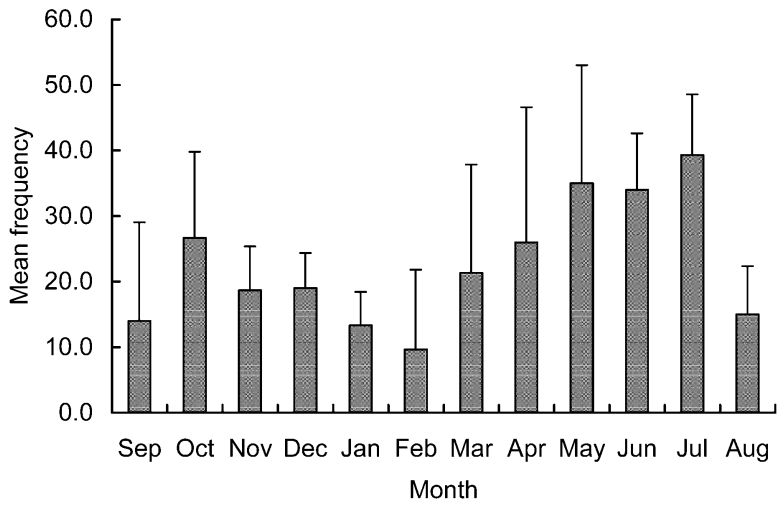

Fig. 2 Seasonal pattern of crop raiding (mean $+\mathrm{SE})$ in Transmara District, 1999-2003.

non-trial farms were undertaken. Three different measures of effectiveness were calculated: (1) The proportion of elephant crop raiding attempts that were repelled during the trial period. (2) The comparative change in number of events on trial and non-trial farms within a conflict zone, before and after the onset of trials. (3) The comparative change in average crop losses during each crop-raiding event on trial and non-trial farms within a conflict zone, before and after the onset of trials.

Individual forays by elephant groups were used as the unit of measurement. If a group of elephants attempted to raid farms successively in the same night this was not considered an independent event, but raids on later dates were. Comparisons were made between two equivalent 17-month periods before and after trial implementation began (April 1999-August 2000 and April 2002-August 2003). Each period included three crop-raiding 'seasons'. Data analysis was conducted using SPSS v. 10 (SPSS, Chicago, USA), using non-parametric tests for statistical comparisons. Spatial data were mapped using ArcView v. 3.2 (ESRI, Redlands, USA).

\section{Results}

\section{Spatial and temporal patterns of crop raiding}

From April 1999 to October 2003, 897 crop raiding incidents were recorded. Of these, $96 \%$ involved maize, the staple local crop. Conflict occurred year-round with peaks corresponding with the two harvest periods (Fig. 2). In both 1999/2000 and 2002/2003, raiding was highest in June-August, with a lesser peak in DecemberJanuary. In the intervening year, 2001/2002, the pattern shifted, with peaks in September-October and MarchApril. Between 1999-2000 and 2002-2003 crop raiding declined by $38 \%$ overall. The median damage per incident of $c .2,000 \mathrm{~m}^{2}$ did not change significantly between periods except in Emarti, where the number of large farms declined. Conflict was spatially clustered, and

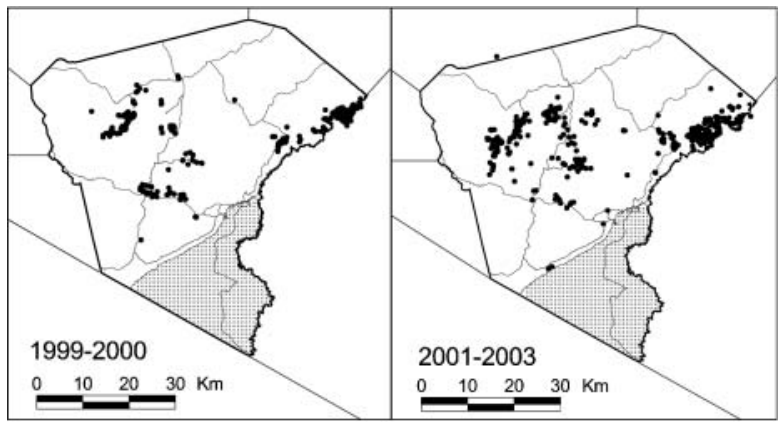

Fig. 3 Comparison of crop raiding locations in Transmara District in 1999-2000 and 2001-2003.

there were few changes in distribution over time (Fig. 3). The greatest conflict was on the boundaries of the elephant range where natural vegetation gives way to increasing human density and cultivation.

\section{Human-elephant conflict mitigation trials}

1) Front line early warning and communal guarding In 2001-2003 the Ilmejoli Farmers Association suffered only one incident of elephant crop raiding, where only one maize stem was destroyed, compared with 14 incidents in 1999-2000 where damage averaged c. $500 \mathrm{~m}^{2}$. Comparing the trial site with a control group of farms revealed a dramatic difference. The control farms witnessed a background decline of $31 \%$ in crop raiding between the two study periods (similar to the district average), compared with a 93\% decline on trial farms.

2) Thunder flashes Thunder flashes repelled elephants for up to 2-3 weeks at a time. Elephants visited the trial farm 21 times during the trial. On nine (43\%) visits elephants successfully raided the farm. Of these, only three took place when thunder flashes were available (Table 1). Crop raiding was successful only $20 \%$ of the time when thunder flashes were available, compared with $100 \%$ of the time when they were not. Moreover, damage during raids when thunder flashes were available was significantly lower than when they were not (median damage $=5 \mathrm{~m}^{2}$ and $1,012 \mathrm{~m}^{2}$, respectively; Mann-Whitney $U=2, \mathrm{P}<0.05)$. However, there was little decline in the number of incidents on the trial farm.

3) Barriers on elephant crop-raiding routes Of 50 records of elephants crossing the Mara River at Emarti, 28\% of cases occurred where there were no barriers. Of the remainder, elephants used several methods to circumvent the barriers, including pushing over posts, breaking wire, or simply going around the barrier on steeper parts of the riverbank. On 17 occasions hippos damaged the barriers when grazing at night or 
Table 1 A comparative assessment of four different mitigation trials over 2 years. Statistics for thunder flashes relate to periods when they were available. The apparent reduction in crop raiding with barriers was probably due to associated guarding.

\begin{tabular}{lccll}
\hline Trial & $\begin{array}{c}\text { Success } \\
\text { rate (\%) }\end{array}$ & $\begin{array}{l}\text { Relative reduction in } \\
\text { crop raiding events (\%) }\end{array}$ & $\begin{array}{l}\text { Relative reduction in } \\
\text { average crop damage (\%) }\end{array}$ & Practicality of method \\
\hline Early warning & 90 & 90 & 100 & $\begin{array}{c}\text { Lowest cost, but requires } \\
\text { significant manpower } \\
\text { Expensive, requires licence, more } \\
\text { effective with early warning } \\
\text { Thunder flashes }\end{array}$ \\
Barriers on elephant routes & 0 & 18 & $50-99$ & $\begin{array}{c}\text { Expensive to construct, disruptive } \\
\text { to other wildlife, \& did not physically } \\
\text { prevent elephant incursions } \\
\text { Chillies expensive to buy; requires } \\
\text { regular re-application of grease }\end{array}$ \\
\hline
\end{tabular}

fighting on the riverbanks. There was one incident of cattle damaging a barrier. An electric fence established to protect nearby commercial wheat fields was also broken four times by elephants. There was a $15 \%$ decline in crop raiding events along the Mara River between 2000 and 2002, less than half of that witnessed across the district as a whole. However, there was a spatial shift in conflict, with farms in Emarti experiencing an $80 \%$ decline in crop raiding, whilst those in adjacent Olongolin without barriers experienced an almost four-fold increase (Fig. 4).

4) Chilli grease deterrent Elephants made three unsuccessful attempts to cross the $1.4 \mathrm{~km}$ perimeter rope in

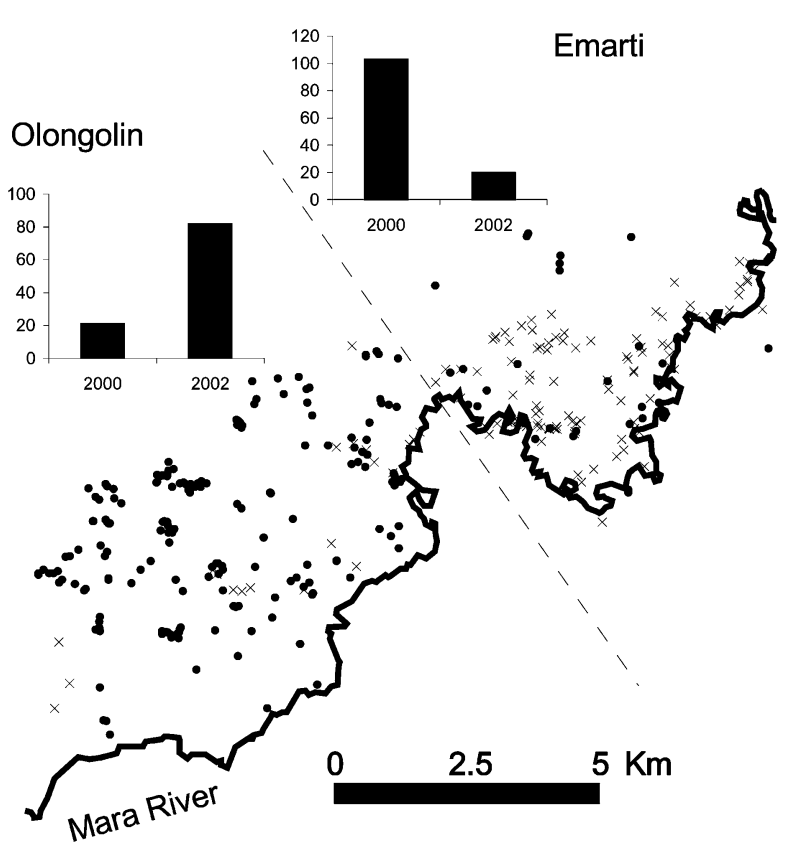

Fig. 4 Changes in the distribution of crop raiding over time along the Mara River between Emarti (barriers) and Olongolin (no barriers). Crop raiding incidents are marked with crosses (2000) and circles (2002). The bar charts show the number of crop raiding events in each area in 2000 and 2002.
Nkararu, apparently deterred by the smell of the chilli grease. After 2 weeks, however, they went around the ends of the rope to enter farms. When chased out of fields by farmers, elephants would not cross the rope but again went around the ends. Unfortunately, the rope and the cowbells were vandalized during a period of ethnic clashes and the trial ceased after 3 months. The farm encircled by chilli rope in the Lolgorien elephant corridor survived for 2 years without elephant crop raiding, despite nine attempts by elephants to enter the farm. A nearby farm without chilli rope was raided seven times during this period and was subsequently abandoned.

\section{Discussion}

\section{Patterns of crop raiding}

Seasonal patterns of elephant crop raiding are common and may be triggered by a decline in quality or availability of wild forage or by crop ripening (Osborn, 2004; Chiyo et al., 2005). The few raids that occur outside these peak periods are mainly exploratory raids by male elephants that appear to be evaluating the ripeness of the crops. Seasonality enables mitigation methods to be deployed intermittently, rather than year-round, and most farmers begin guarding 2 months prior to harvest.

Spatial patterns appear relatively robust over time, and are related to underlying patterns of cultivation (Sitati et al., 2003), focused particularly on the boundaries between farm and forest areas (Hill, 1997; Barnes et al., 2003). Again this permits the strategic deployment of defence methods; if the front line of farms can be defended, those behind may also be protected.

\section{Evaluating mitigation methods}

The overall decline in crop raiding between the two monitoring periods may have been because of the increased rainfall, which increases grass productivity 
thereby removing one trigger for crop raiding (Osborn, 2004). However, against this background decline the impact of some mitigation trials can be detected, although success is mixed (Table 1). Active guarding and deterrent methods are better than passive barriers alone. The use of watchtowers and torches to provide early warning, for example, enabled farmers to respond before elephants entered farms, with a dramatic effect upon their ability to defend their farms.

Thunder flashes were most effective in conjunction with early warning. They are, however, expensive, restricted to licenced personnel and, because the supply often ran out, the number of raids was not reduced. Thus, they are unlikely to be a suitable method for widespread use and communities are better off using cheaper, safer methods that they can implement themselves.

Barriers along the Mara River failed because they crossed habitual elephant routes and were therefore regularly challenged. It is possible that a decline in crop raiding near to fenced paths and an increase in adjacent unfenced areas was a result of displacement, but this effect was more likely because of guards at the barriers alerting farmers to elephant approaches rather than to any effect of the barriers themselves. Only where chilli was applied to barriers did they have any effect, but only if fields were entirely encircled by fences. Elephants easily bypassed a chilli fence once they learnt that it was of finite length. The same was found with an electric fence on the boundary of Tsavo East National Park, where conflict declined towards the centre of the fence but increased in farms at each end where elephants went around (Smith \& Kasiki, 1999).

The success of chilli rope fences is surprising given the relative frailty of the rope as a physical barrier but confirms the deterrent power of chilli (Osborn \& Parker, 2002). This is greatly beneficial if it allows some easing of nightly guarding effort. However, continuous application of chilli grease, on at least a weekly basis, is important to deter elephants continually, because of rain washing it off.

\section{Methodological issues}

Evaluations of conflict mitigation measures vary in their level of scientific rigour, from gathering farmers' perceptions (Nyhus et al., 2000), to statistical analyses of the correlates of conflict intensity (Naughton-Treves, 1998; Ogada et al., 2003). However, few studies undertake experimental manipulation. Studies that have been conducted were either treatment-response trails on target farms (O'Connell-Rodwell et al., 2000) or post-treatment spatial comparisons between treatment and control farms (Osborn \& Parker, 2002). Yet without time series comparisons of treatment and control farms before and after treatments take place it is not possible to distinguish treatment effects from other background changes or existing differences between farms. Using this approach our study provided rigorous, comparative evidence of the effectiveness of different mitigation methods over several conflict seasons. Its weaknesses are its lack of replication or random allocation of farms into treatment and control groups, although such groups were chosen to be as comparative as possible, given the willingness of farmers to participate in trials.

\section{The viability of community-based mitigation methods}

In the absence of government support the development of cheap and simple farm-based mitigation strategies offers the best solution for human-elephant conflict (Osborn \& Parker, 2003). If successful, they may allow elephants to continue to utilize the greater part of their unprotected range. However, there are some caveats. Firstly, if better protection of some farms simply displaces the problem to neighbouring farms ( $\mathrm{O}^{\prime}$ ConnellRodwell et al., 2000) then these small-scale mitigation methods are not reducing overall levels of conflict. Elephants raid crops because they are nutritionally valuable, and although they respond to risk they are unlikely to avoid unprotected farms. Farm-based mitigation must be deployed much more widely before significant reductions in human-elephant conflict are likely.

Secondly, demonstrable success of farm-based methods does not guarantee their uptake by farmers. Although farmers believe that guarding and deterrents are the most effective methods of mitigation, they also fear that elephants will habituate to most methods deployed against them, (Bell, 1984; Nyhus et al., 2000). Many communities want elephants removed or fenced in protected areas because the elephants are of no benefit and perceived as being owned by the State (Sitati, 2003). More importantly, mitigation incurs significant costs for subsistence farmers, so it is understandable that farmers rely on family members, including children, to guard their fields (Hill, 2000) and why even torch batteries may be too expensive for them. Even chilli becomes prohibitively expensive if not locally grown (Parker \& Osborn, 2006). Yet, to date, few outreach programmes from donors or wildlife departments directly support community efforts to live with wildlife, preferring instead to support development projects and school bursaries (Walpole \& Thouless, 2005). Without further demonstration of successful farm-based methods, and associated support from donors and NGOs, uptake by farmers will remain limited, and the most vulnerable will be forced to abandon their farms (Naughton-Treves \& Treves, 2005).

Thirdly, mitigation will not succeed without cooperation within and between communities. Theft, vandalism and political instability all affected efforts to defend 
farms from elephants. Elsewhere, residents have been known to take wire from game fences to make snares, even though this exacerbated crop raiding (M. Borner, pers comm.). These difficulties are compounded by land privatization in East Africa and armed conflict in Central Africa, both of which undermine collective action.

Finally, successful mitigation may simply encourage greater cultivation in elephant ranges. When the Kenya government offered compensation for crop raiding in the late 1980s, cultivation in Transmara increased (Sitati, 2003). At least two farmers in Lolgorien have begun to cultivate larger fields because of the successes of early warning and chilli ropes. Defending farms addresses the symptoms of conflict but not the underlying cause, which is increasing settlement and cultivation within elephant ranges (Barnes, 2002). For farm-based mitigation methods to provide a lasting solution to elephant conflict they must be accompanied by appropriate land use planning and incentives to conserve natural wildlife habitat.

\section{Conclusions and recommendations}

This small-scale, comparative study suggests that the sustained implementation of traditional and novel farmbased methods is effective at reducing human-elephant conflict. Based on these results we make the following recommendations:

- Combine early warning, guarding, and chilli grease deterrents to guard front line farms.

- Make farmers themselves responsible for implementing mitigation methods.

- Expand the testing and demonstration of mitigation trials.

- Support local chilli production as an alternative cash crop and for use in chilli-based deterrents.

- Lobby for sustainable support from governments and donors for community-based conflict mitigation.

- Ensure that income from wildlife (e.g. tourism revenues) is used to support conflict mitigation activities.

- Develop land use plans that regulate cultivation within elephant ranges.

- Identify and encourage alternatives to farming.

A new phase of this study is replicating these successful methods over 10 sites within Transmara District, and links are being made with other human-elephant conflict zones in Kenya, Tanzania, Thailand and Cambodia to enable further replication and comparison, particularly of chilli-based deterrents, between ecosystems.

\section{Acknowledgements}

This research was undertaken with the kind permission of the Office of the President of the Republic of Kenya, with funding from the Darwin Initiative for the Survival of Species (Grant nos. 162/6/131 and 162/10/003) and the African Elephant Program of WWF-International (Grant no. 9F0727). Kenya Wildlife Service, Durrell Institute of Conservation and Ecology, and WWFEARPO provided technical and logistical support, and the community scouts and other residents of Transmara provided field support. Holly Dublin, Patrick Omondi, Richard Hoare, P.J. Stephenson and Nigel LeaderWilliams provided technical advice, and we are grateful to Guy Parker and Loki Osborn for advice on the merits of chilli pepper as a mitigation tool.

\section{References}

Barnes, R.F.W. (2002) Treating crop-raiding elephants with aspirin. Pachyderm, 33, 96-99.

Barnes, R.F.W., Boafo, Y., Nandjui, A., Dubiure, U., Hema, E.M., Danquah, E. \& Manford, M. (2003) An Overview of Crop Raiding by Elephants around the Kakum Conservation Area: Part 2 Technical Report. Unpublished Report, Conservation International, Washington, DC, USA.

Bell, R.H.V. (1984) The man-animal interface: an assessment of crop damage and wildlife control. In Conservation and Wildife Management in Africa (eds R.H.V. Bell \& E. McShane-Caluzi), pp. 387-416. US Peace Corps, Lilongwe, Malawi.

Blanc, J.J., Thouless, C.R., Hart, J.A., Dublin, H.T., Douglas-Hamilton, I., Craig, C.G. \& Barnes, R.F.W. (2003) African Elephant Status Report 2002: An Update from the African Elephant Database. IUCN/SSC African Elephant Specialist Group, IUCN, Gland, Switzerland.

Chiyo, P.I., Cochrane, P.E., Naughton, L. \& Basuta, G.I. (2005) Temporal patterns of crop raiding by elephants: a response to changes in forage quality or crop availability? African Journal of Ecology, 43, 48-55.

Duncan, E. (2003) A chilli day keeps the elephants away. East African Standard, 15 October edition, VIII.

Hill, C.M. (1997) Crop-raiding by wild vertebrates: the farmer's perspective in an agricultural community in western Uganda. International Journal of Pest Management, 43, 77-84.

Hill, C.M. (2000) Conflict of interest between people and baboons: crop raiding in Uganda. International Journal of Primatology, 21, 299-315.

Hill, C.M., Osborn, F.V. \& Plumptre, A.J. (2000) Human-wildlife Conflict: Identifying the Problem and Possible Solutions. Albertine Rift Technical Report Series, No.1, Wildlife Conservation Society, New York, USA.

Hoare, R.E. (1999) A Standard Data Collection and Analysis Protocol for Human-elephant Conflict Situations in Africa. IUCN African Elephant Specialist Group, Nairobi, Kenya.

Hoare, R.E. (2000a) African elephants and humans in conflict: the outlook for coexistence. Oryx, 34, 34-38.

Hoare, R.E. (2000b) A Review of Compensation Schemes for Agricultural and Other Damage Caused by Elephants. IUCN African Elephant Specialist Group, Nairobi, Kenya.

Hoare, R.E. (2001) A Decision Support System for Managing Human-elephant Conflict Situations in Africa. IUCN African Elephant Specialist Group, Nairobi, Kenya.

Hoare, R.E. \& du Toit, J.T. (1999) Coexistence between people and elephants in African savannas. Conservation Biology, 13, 663-639. 
Naughton-Treves, L. (1998) Predicting patterns of crop damage by wildlife around Kibale National Park, Uganda. Conservation Biology, 12, 156-168.

Naughton-Treves, L. \& Treves, A. (2005) Socio-ecological factors shaping local support for wildlife: crop-raiding by elephants and other wildlife in Africa. In People and Wildlife: Conflict and Coexistence (eds R. Woodroffe, S. Thirgood \& A. Rabinowitz), pp. 252-277. Cambridge University Press, Cambridge, UK.

Njumbi, S., Waithaka, J., Gachago, S., Sakwa, J., Mwathe, K., Mungai, P., Mulama, M., Mutinda, H., Omondi, P. \& Litoroh, M. (1996) Translocation of elephants: the Kenyan experience. Pachyderm, 22, 61-65.

Nyhus, P.J., Tilson, R. Sumianto (2000) Crop-raiding elephants and conservation implications at Way Kambas National Park, Sumatra, Indonesia. Oryx, 34, 262-274.

O'Connell-Rodwell, C.E., Rodwell, T., Rice, M. \& Hart, L.A. (2000) Living with the modern conservation paradigm: can agricultural communities co-exist with elephants? A five-year case study in East Caprivi, Namibia. Biological Conservation, 93, 381-391.

Ogada, M.O., Woodroffe, R., Oguge, N.O. \& Frank, L.G. (2003) Limiting depredation by African carnivores: the role of livestock husbandry. Conservation Biology, 17, 1521-1530.

Osborn, F.V. (2002) Capsicum oleoresin as an elephant repellent: field trials in the communal lands of Zimbabwe. Journal of Wildife Management, 66, 674-677.

Osborn, F.V. (2004) Seasonal variation of feeding patterns and food selection by crop-raiding elephants in Zimbabwe. African Journal of Ecology, 42, 322-327.

Osborn, F.V. \& Parker, G.E. (2002) Community-based methods to reduce crop losses to elephants: experiments in the communal lands of Zimbabwe. Pachyderm, 33, 32-38.

Osborn, F.V. \& Parker, G.E. (2003) Towards an integrated approach for reducing the conflict between elephants and people: a review of current research. Oryx , 37, 80-84.

Osborn, F.V. \& Rasmussen, L.E.L. (1995) Evidence for the effectiveness of an oleo-resin capsicum aerosol as a repellent against wild elephants in Zimbabwe. Pachyderm, 2, 55-64.

Parker, G.E. \& Osborn, F.V. (2006) Investigating the potential for chilli to reduce human-wildlife conflict in Zimbabwe. Oryx, 40, 343-346.

Sitati, N.W. (2003) Human-elephant conflict in Transmara District adjacent to Masai Mara National Reserve. PhD thesis, University of Kent, Canterbury, UK.

Sitati, N.W., Walpole, M.J. \& Leader-Williams, N. (2005) Factors affecting susceptibility of farms to crop raiding by African elephants: using a predictive model to mitigate conflict. Journal of Applied Ecology, 42, 1175-1182.

Sitati, N.W., Walpole, M.J., Smith, R.J. \& Leader-Williams, N. (2003) Predicting spatial aspects of human-elephant conflict. Journal of Applied Ecology, 40, 667-677.

Smith, R.J. \& Kasiki, S. (1999) A Spatial Analysis of Human-elephant Conflict in the Tsavo Ecosystem, Kenya. African
Elephant Specialist Group report, IUCN/SSC, Gland, Switzerland.

Sukumar, R. (1989) The Asian Elephant: Ecology and Management. Cambridge University Press, Cambridge, UK.

Sutherland, W.J., Pullin, A.S., Dolman, P.M. \& Knight, T.M. (2004) The need for evidence-based conservation. Trends in Ecology and Evolution, 19, 305-308.

Tchamba, M.N. (1996) History and present status of the human/elephant conflict in the Waza-Logone region, Cameroon, West Africa. Biological Conservation, 75, 35-41.

Thouless, C.R. \& Sakwa, J. (1995) Shocking elephants: fences and crop raiders in Laikipia district, Kenya. Biological Conservation, 72, 99-107.

Walpole, M.J., Karanja, G.G., Sitati, N.W. \& Leader-Williams, N. (2003) Wildlife and People: Conflict and Conservation in Masai Mara, Kenya. Wildlife and Development Series No.14, International Institute for Environment and Development, London, UK.

Walpole, M.J., Ndoinyo, Y., Kibasa, R., Masanja, C., Somba, M. \& Sungura, B. (2004) An Assessment of Human Elephant Conflict in the Western Serengeti. Unpublished Report, Frankfurt Zoological Society, Arusha, Tanzania.

Walpole, M.J. \& Thouless, C.R. (2005) Increasing the value of wildlife through non-consumptive use? Deconstructing the myths of ecotourism and community-based tourism in the tropics. In People and Wildlife: Conflict and Coexistence (eds R. Woodroffe, S. Thirgood \& A. Rabinowitz), pp. 122-139. Cambridge University Press, Cambridge, UK.

Woodroffe, R. \& Ginsberg, J.R. (1998) Edge effects and the extinction of populations inside protected areas. Science, 280, 2126-2128.

Woodroffe, R., Thirgood, S. \& Rabinowitz, A. (2005) People and Wildlife: Conflict and Coexistence. Cambridge University Press, Cambridge, UK.

\section{Biographical sketches}

Noah Sitati has studied land use change and human wildlife conflict in the Mara ecosystem for 10 years. He manages the Transmara Human Elephant Conflict Project for the Durrell Institute of Conservation and Ecology and WWF, working closely with local Maasai communities. He is a member of the IUCN/SSC African Elephant Specialist Group.

Matt Walpole specializes in multi-disciplinary approaches to conservation. He has studied tourism in relation to Komodo dragons, black rhino population recovery and human-wildlife conflict in Africa. He is now coordinating a global project exploring the links between livelihoods and conservation for Fauna \& Flora International. 